\title{
Some Contributions to the Microscopic Innervation of the Coccygeal Body and its Surroundings
}

\author{
By \\ Kinziro Kubota, M. D. \\ Department of Anatomy, Tokyo Medical \& Dental University, Tokyo
}

Up to date, there have been few papers concerning the microscopic innervation of the coccygeal bodies. Recently in $1955 \mathrm{Dr}$. H. Sat o made a study on this subject and stated that the coccygeal body is richly innervated by abundant fine non-myelinated and a few thick medullated nerve fibers and that paraganglionic cells are observed in the stroma of the organ.

The author described in a previous paper (1954) that the coccygeal body is innervated by the sympathetic nerves and the spinal nerves $\left(\mathrm{S}_{4}, \mathrm{~S}_{5}\right.$ and $\left.\mathrm{Co}\right)$. Since then the author had an opportunity to investigate on the coccygeal bodies in man the microscopic nerve supply of this organ and its surroundings with the silver-impregnated frozen sections.

\section{Observation}

The organ is richly supplied by vegetative nerve fibers; the sympathetic fibers, which originate from the ganglion impar, and the parasympathetic fibers, probably accompanied by the spinal nerves.

In Figure 1 it is seen that the stroma of the organ is richly innervated by abundant fine nerve fibers and a few thick nerve fibers. The abundant fine nerve fibers are presumed to supply the smooth muscle fibers, which are situated around the parenchymal cells of the arterio-venous anastomosis.

Figure 2 represents the hilus portion of the coccygeal body in human adult. Figure 3 is a higher magnification of Figure 2. In the coccygeal bodies the sensory nerve endings have also been observed representing various types of nerve endings. In Figure 3 are demonstrated the complex ramified terminations of the sensory nerves, which lie in the stroma between the anastomoses. The terminal fibers 


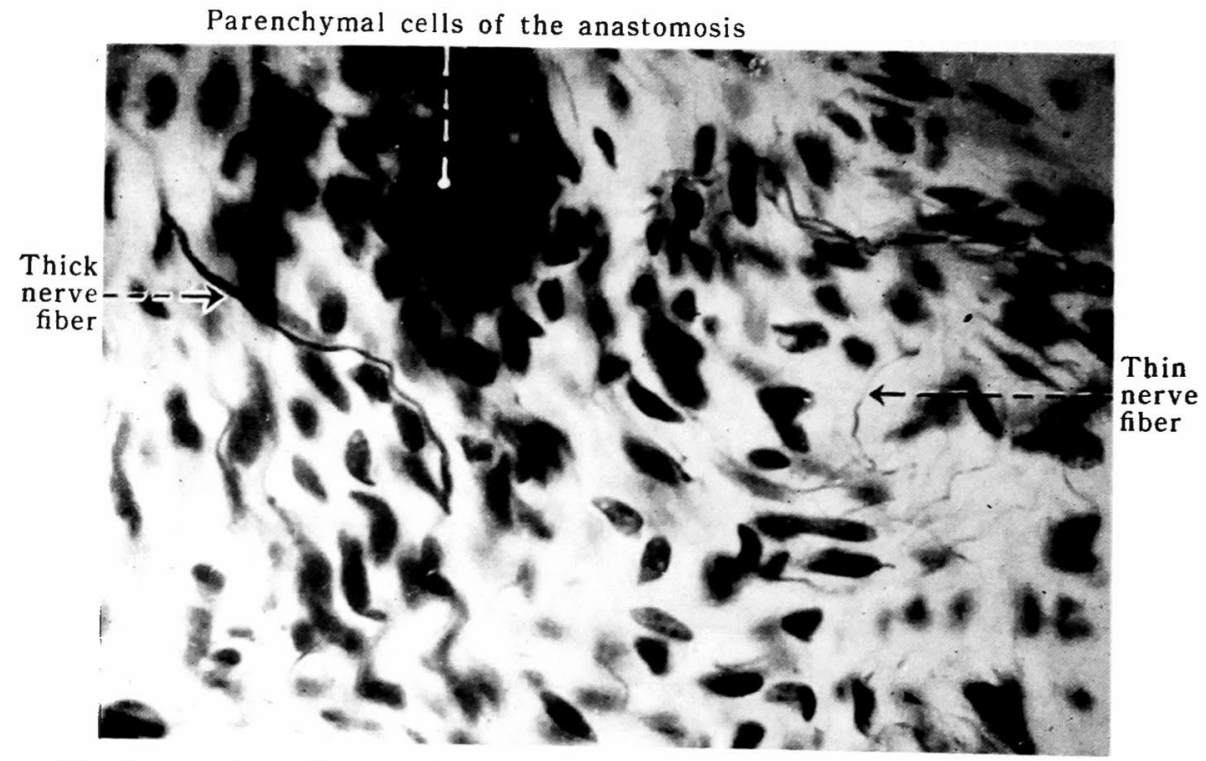

Fig. 1. A photomicrograph to show the rich innervation in the stroma of the coccygeal body in human adult. There are seen numerous fine nerve fibers interlacing to form a plexus with each other and a few thick nerve fibers. Silver-impregnation method.

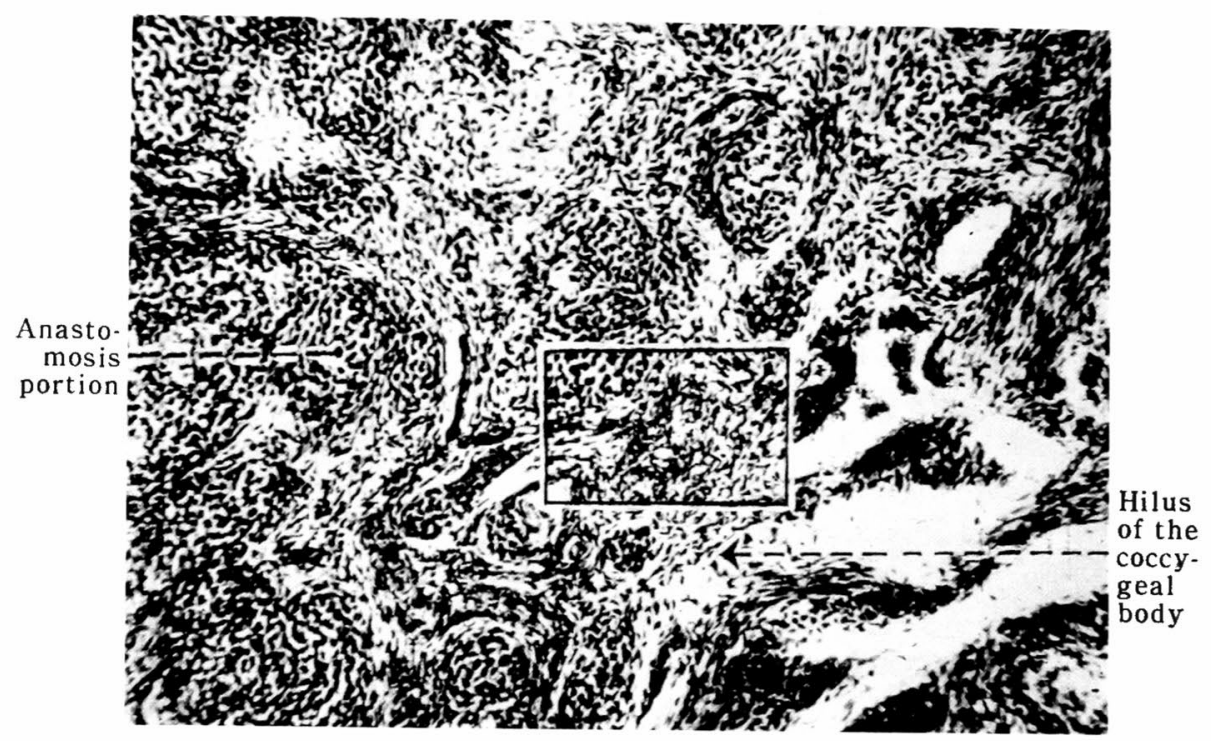

Fig. 2. Hilus portion of the coccygeal body in human adult. Brock-stain by silver-impregnation method. 


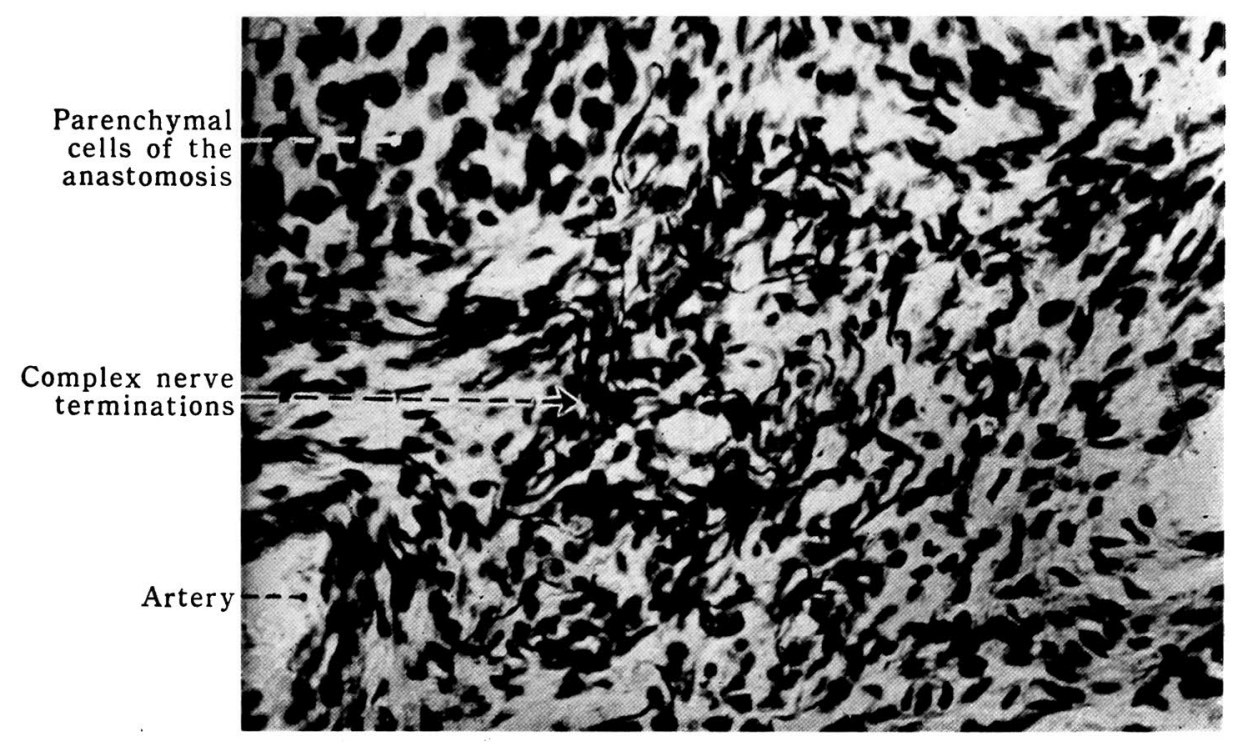

Fig. 3. Higher magnification of the area indicated by a rectangle in Fig. 2 , to show the complex ramified terminations of the sensory nerves found in the hilus stroma of the coccygeal body.

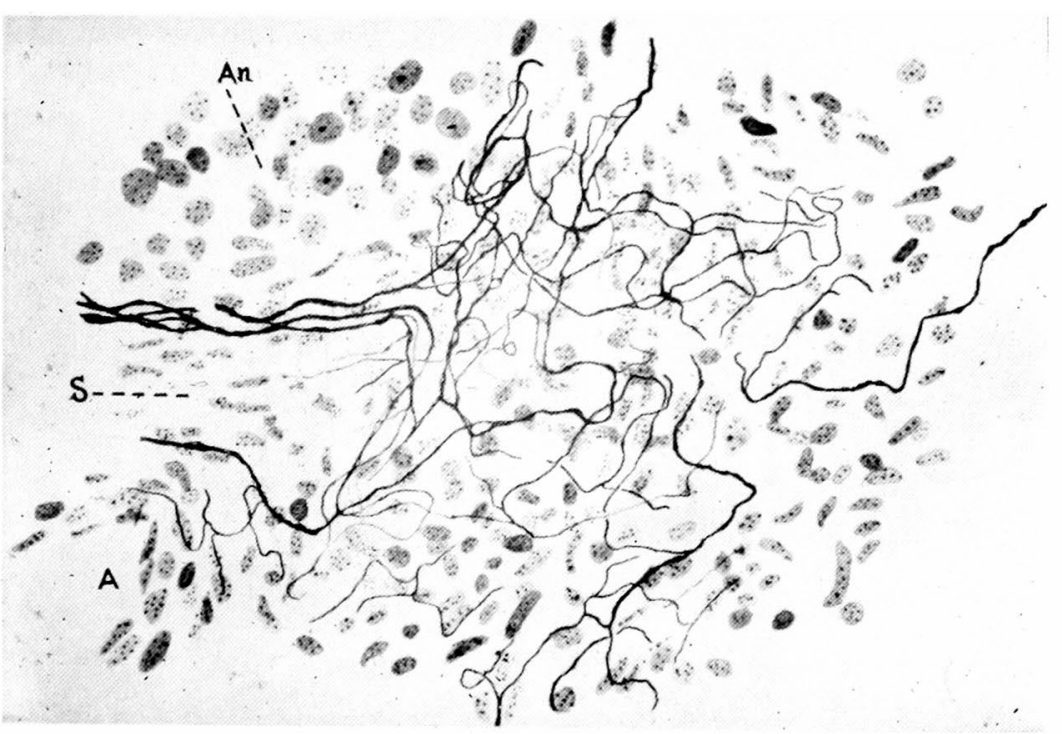

Fig. 4. A diagram of Fig. 3. The nerve fibers are closely related to the peripheral zone of the parenchymal cells of the anastomosis and the wall of the blood vessel in the stroma. A : Artery, An: Arteriovenous anastomosis, S: Stroma.

the nerve endings are closely related to the peripheral layer of the parenchymal cells of the anastomosis. Figure 4 is a diagram of Figure 3. 


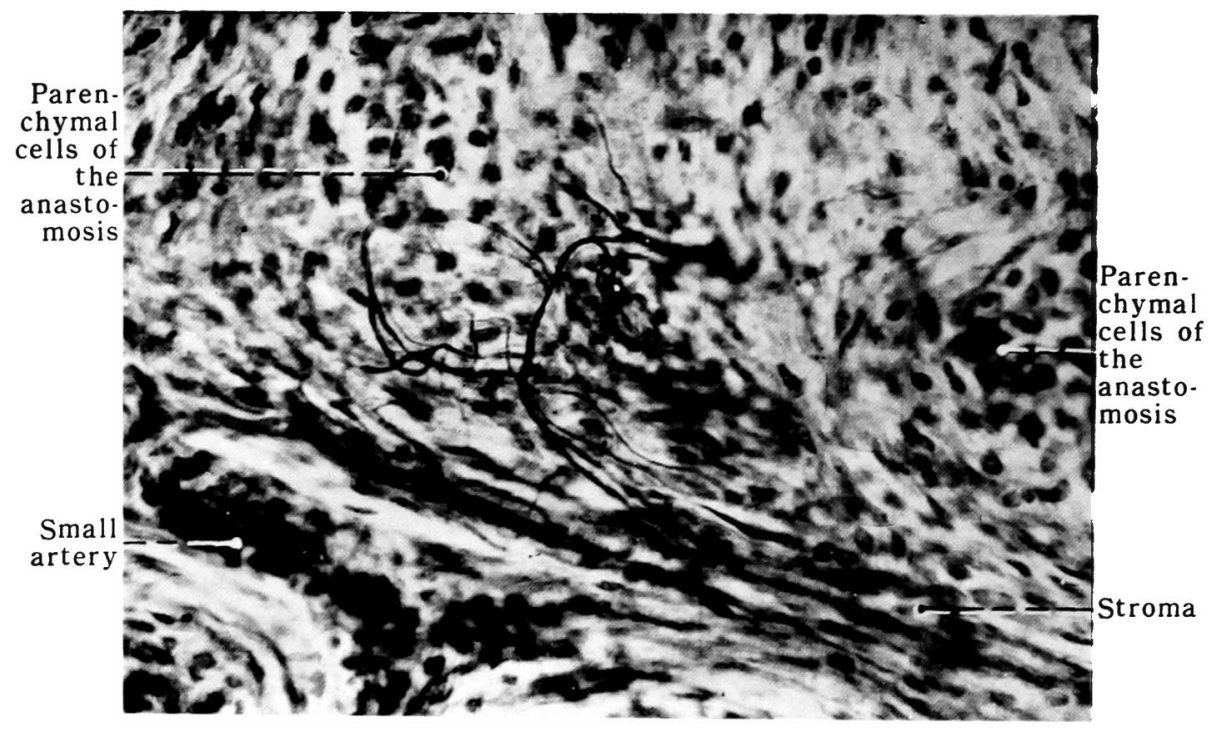

Fig. 5. A photomicrograph showing the complex sensory nerve terminations in the stroma of the coccygeal body in human adult. Silverimpregnation method.

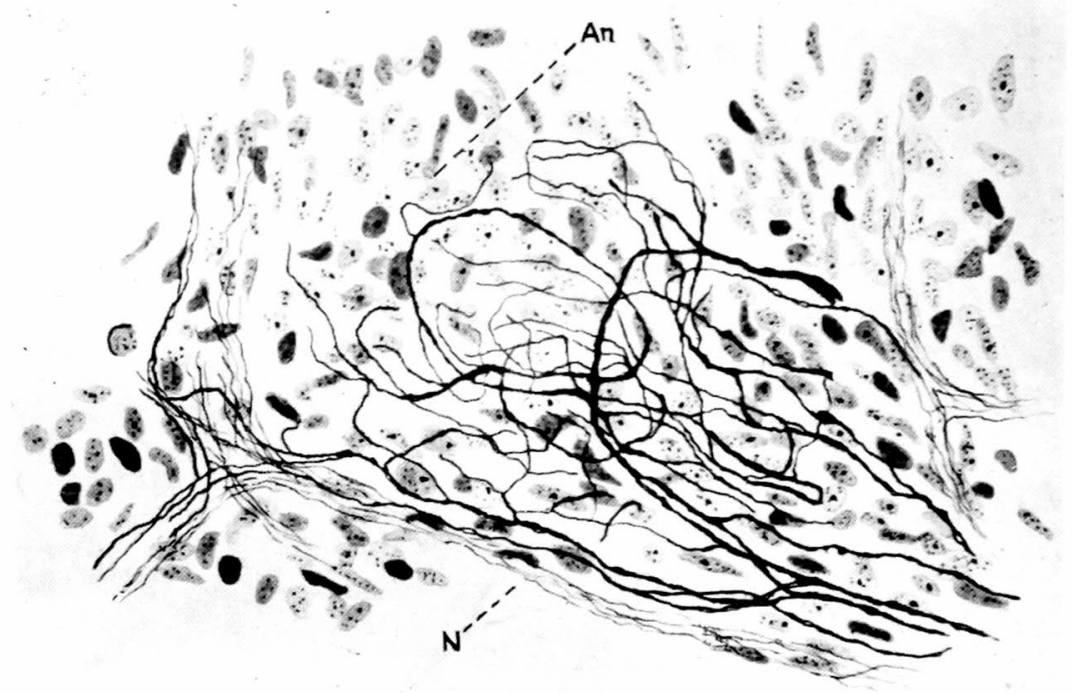

Fig. 6. A diagram of Fig. $\overline{5}$. The nerve fibers are actually terminated in the parenchymal cells of the anastomosis and in the stroma. In the stroma a delicate network of fine nerve fibers is seen. An: Arterio-venous anastomosis, N: Nerve fiber bundles. 


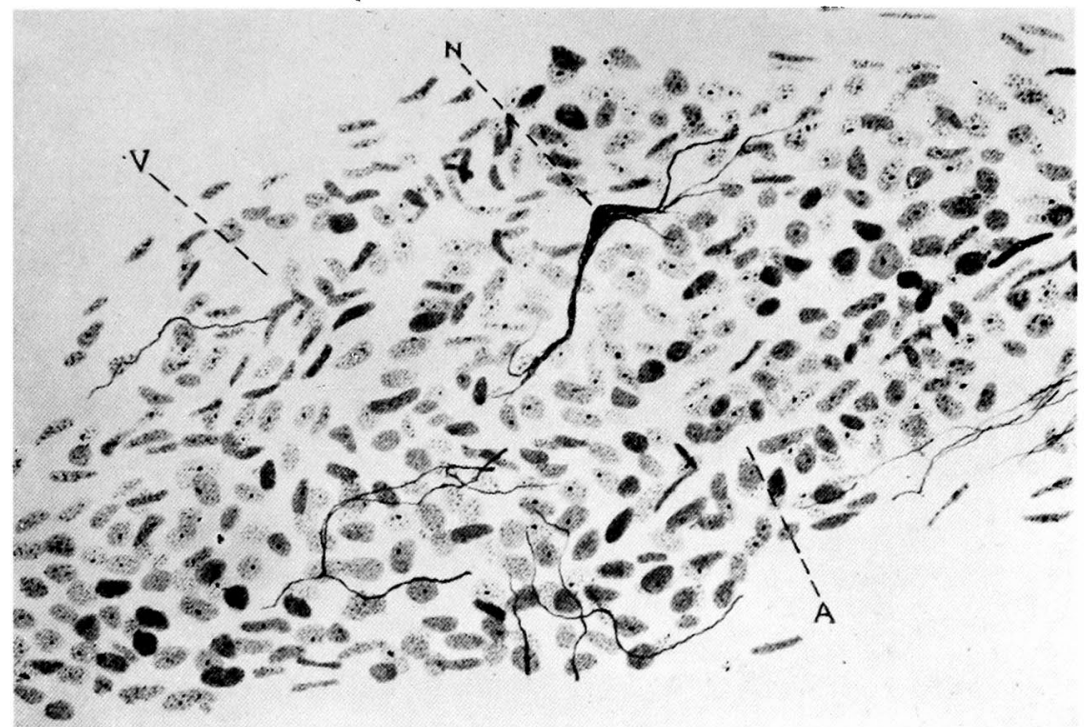

Fig. 7. A diagram of an embryonic coccygeal body in a 4-month old human fetus. In the body during the period when the embryonic parenchymal cells (angioblastic cells) are actually differentiated from the terminal portion of the median sacral artery, the non-myelinated nerve fibers are poorly traced. Silver-impregnation method. A: Terminal portion of the median sacral artery, $N$ : Non-myelinated nerve fiber bundle, $V$ : Vein.

In Figure 5 the glomerular, complex nerve ending of the sensory nerves, which terminate in the parenchymal layer of the anastomosis, is shown. Figure 6 is a diagram of Figure 5.

The free nerve endings of the sensory nerves are also frequently observed here and there in the stroma of this organ.

These sensory nerve endings mentioned above may have an important significance as the chemo-receptory organism of the coccygeal body, which is a vaso-regulating organ.

Figures 7 and 8 represent the microscopic innervation of the undeveloped coccygeal bodies in human fetuses. Figure 7 is a diagram of an embryonic coccygeal body in 4-month old fetus. Non-myelinated nerve fibers have been traced in the body during the period when the embryonic parenchymal cells (angioblastic cells) actually originate from the terminal portion of the median sacral artery. In Figure 8 the embryonic coccygeal body, which is abundantly innervated by non-medullated nerve fibers, is depicted in a 7-month old fetus.

Figure 9 represents a small ganglion which has been found in or near the nerve fiber bundles supplying the organ from the ganglion 


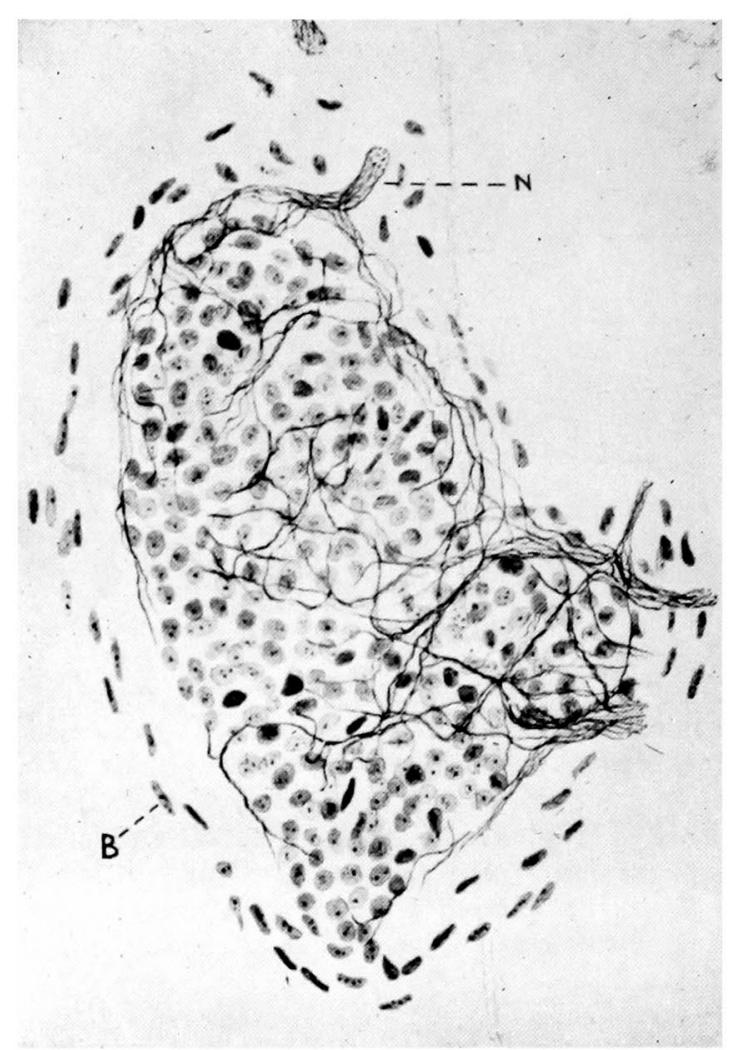

Fig. 8. A diagram of an embryonic coccygeal body supplied by abundant non-medullated nerve fibers. A 7-month old fetus. Silver-impregnation method. B: Surrounding connective tissue sheath, $\mathrm{N}$ : Non-medullated nerve fiber bundle.

impar. The ganglion is composed of several multipolar nerve cells. The nerve cells have been often found sporadically in the nerve fiber bundles without forming a group. These small atypical ganglions are considered to be phylogenetical as the terminal one of the sympahetlic nerve trunk ganglions in human body. No nerve cells have been observed in the stroma of the coccygeal body.

In the surrounding tissue of the coccygeal bodies various types of end-organs of the sensory nerves are observed; the free nerve ending, non-capsulated nerve ending and encapsulated nerve ending.

In Figure 10 a specific non-capsulated nerve ending which is found in the connective tissue near the coccygeal body of a human adult is depicted.

Figures 11, 12 and 13 are drawings of the encapsulated nerve 


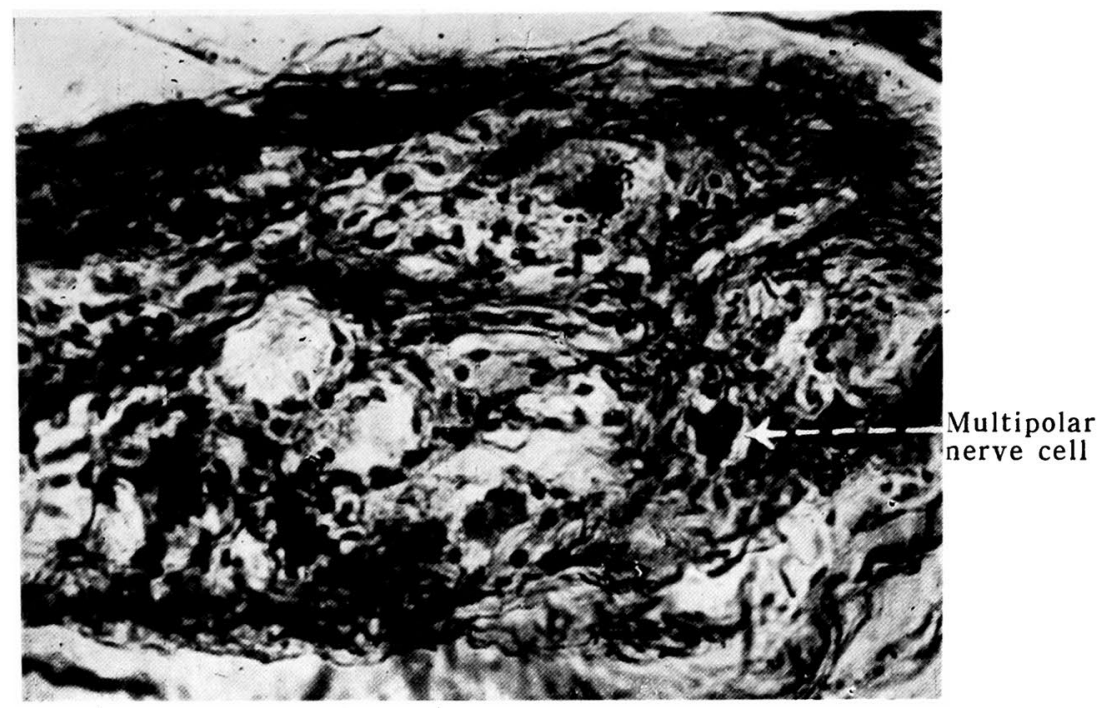

Fig. 9. A small ganglion which is found in the nerve fiber bundles entering the coccygeal body of the human adult. The ganglion is composed of multipolar nerve cells. Brock-stain by silverimpregnation method.

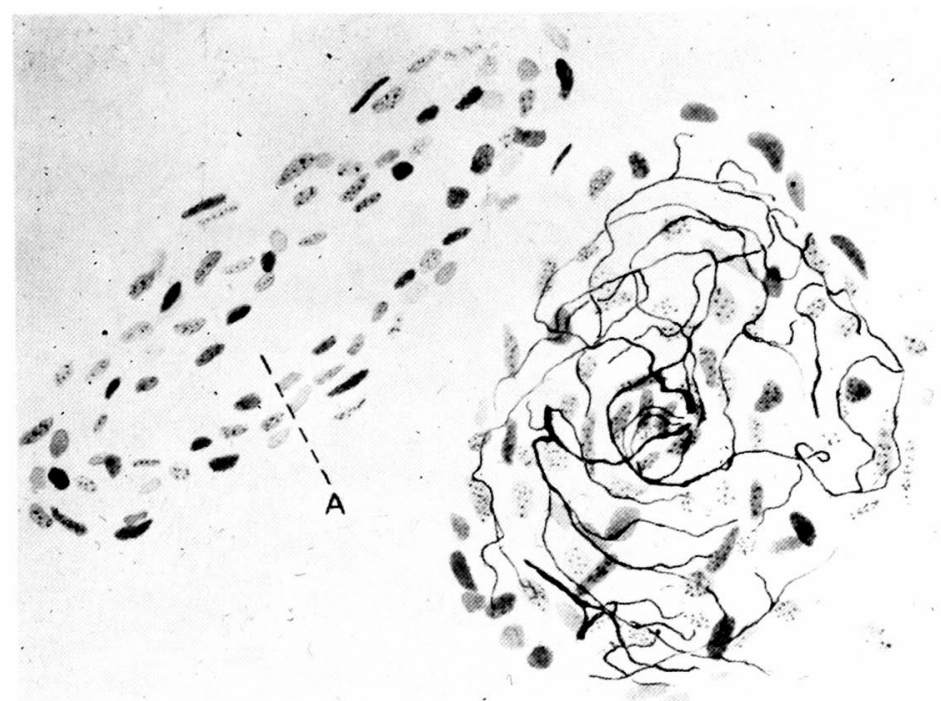

Fig. 10. A diagram of a specific non-capsulated nerve corpuscle, which is found in the connective tissue surrounding the coccygeal body of human adult, lying near the wall of the artery. Silver-impregnation method. A : Artery. 


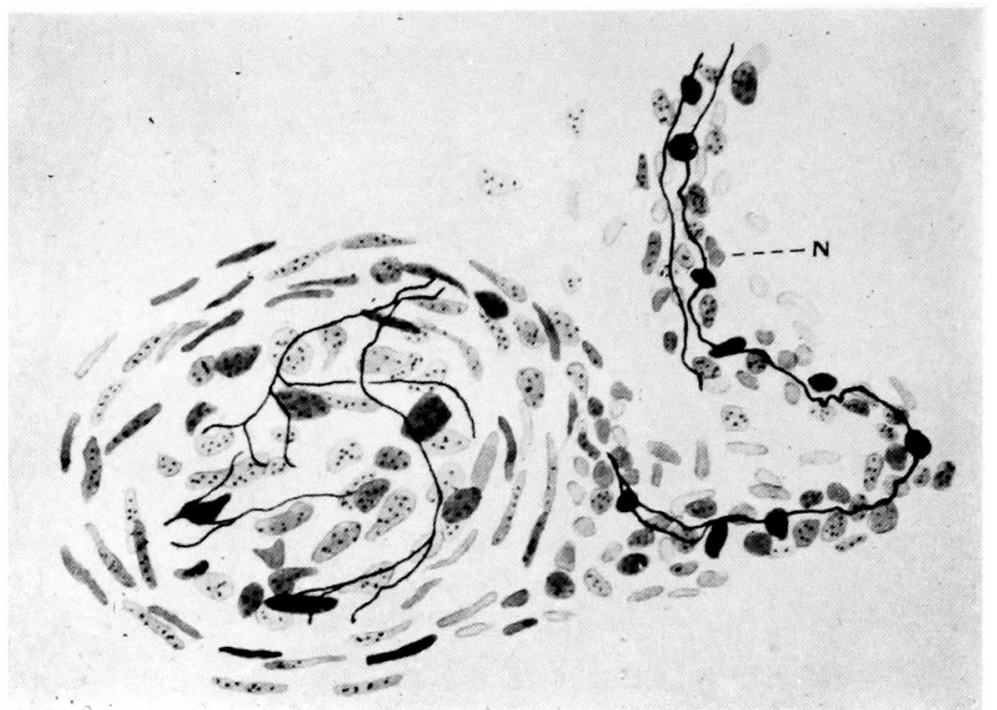

Fig. 11. A diagram of an encapsulated nerve corpuscle, which is found in the surroundings of the coccygeal bodies in a young body, lying near or in the bifurcation of the branches of the blood vessels supplying the coccygeal bodies. 25 days after birth. Silver-impregnation method. N: Myelinated nerve fibers with Schwann's cells.

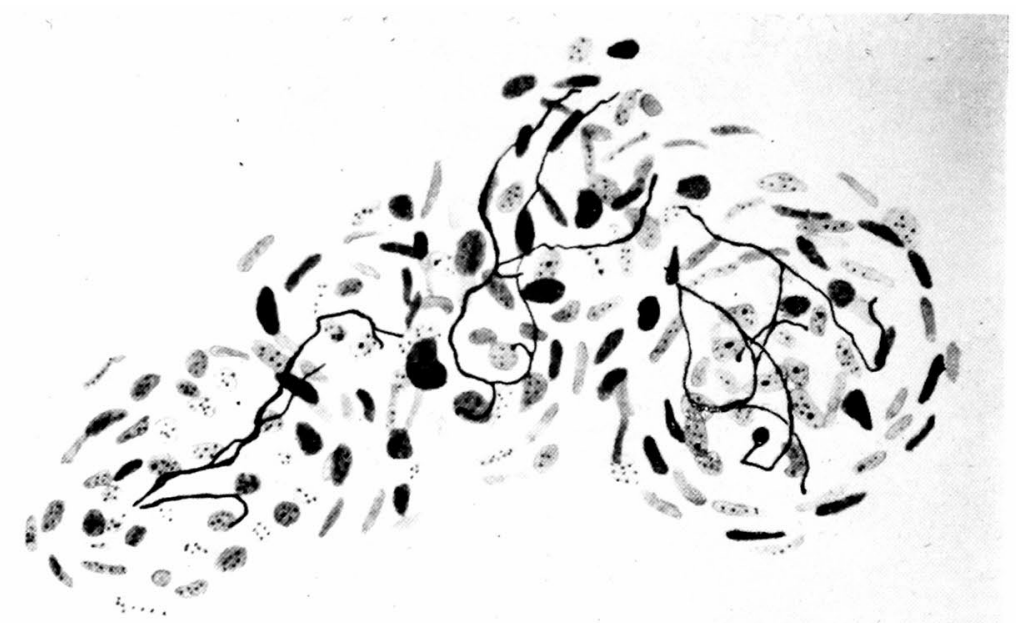

Fig. 12. A diagram of the encapsulated nerve corpuscles, which are observed in the bifurcation of the branches of the blood vessels supplying the coccygeal bodies. 25 days after birth. Silver-impregnation method. 
Some Contributions to the Microscopic Innervation of the Coccygeal Body 71

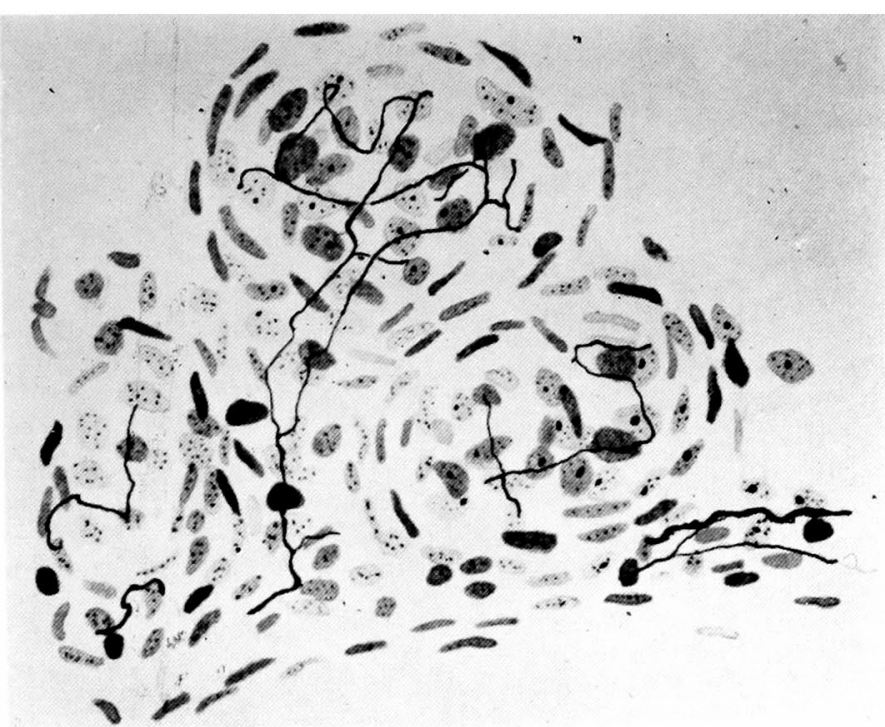

Fig. 13. A diagram of three encapsulated nerve corpuscles, which are found near the bifurcation of the branches of the blood vessel entering the coccygeal bodies, uniting together. 25 days after birth. Silver-impregnation method.

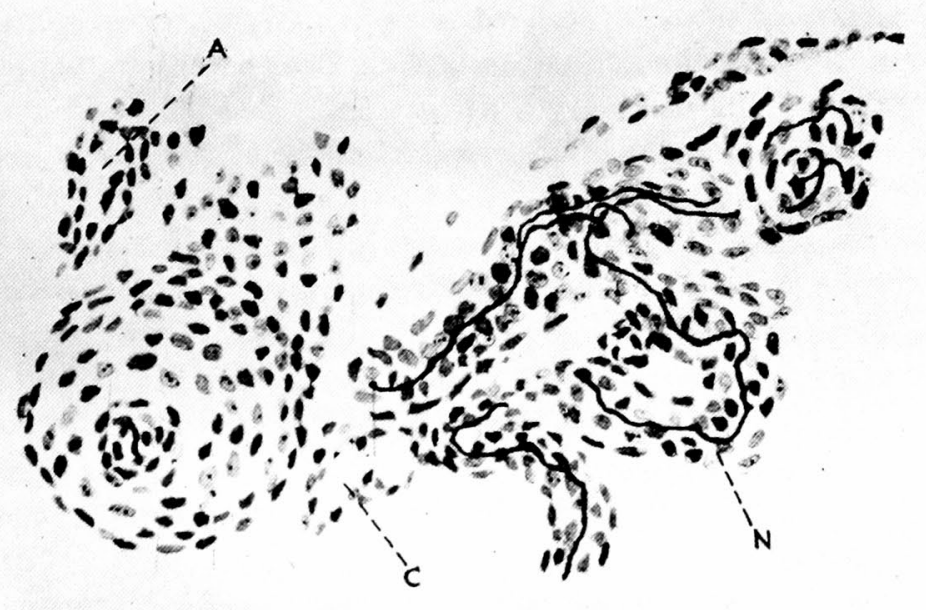

Fig. 14. A diagram of a lamellar nerve corpuscle, which is found in the connective fat tissue surrounding the coccygeal bodies in a young body. 25 days after birth. Silver-impregnation method. A : Artery, $C$ : Vein, $\mathrm{N}$ : Nerve fiber with the myelinic coat. 


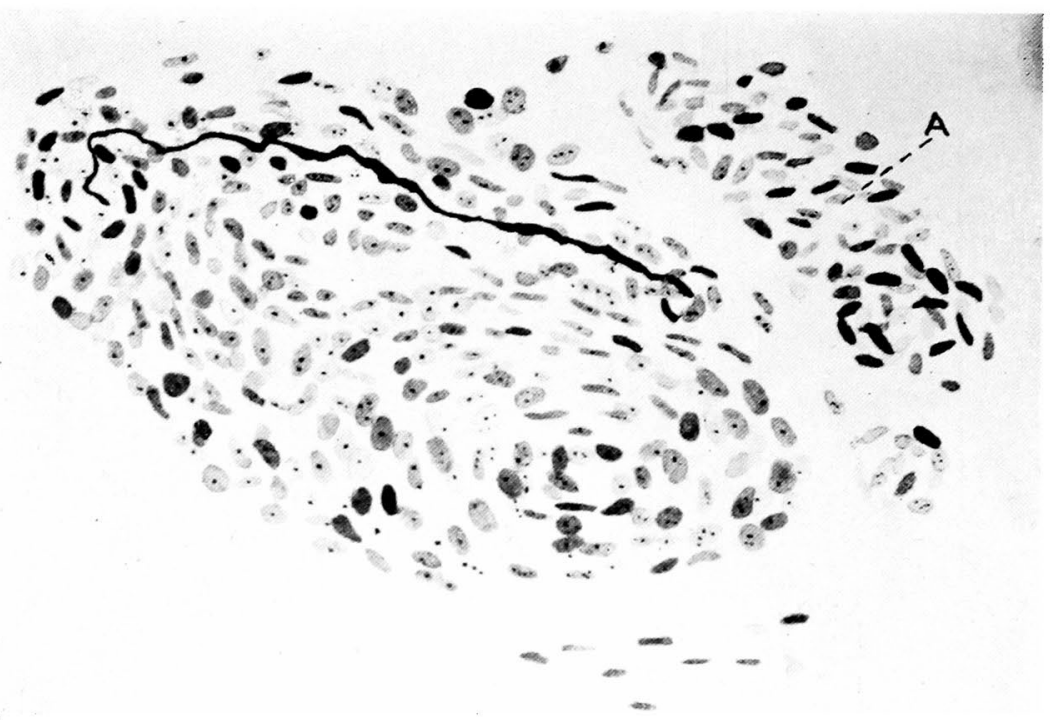

Fig. 15. A diagram of a large lamellar nerve corpuscle, which is found in the surroundings of the coccygeal bodies, lying near the wall of the artery. 25 days after birth. Silver-impregnation method. A : Artery.

endings, which lie near the bifurcation of the branches of the blood vessels supplying the coccygeal bodies. In Figure 13 three encapsulated nerve corpuscles are united together. These encapsulated nerve corpuscles resemble the end-organ of Krause in microscopic appearance. These encapsulated nerve corpuscles may be closely related to the regulation of the vasculation through the blood vessels supplying the coccygeal bodies.

Also in the neighborhood of the coccygeal bodies the Pacinian corpuscles are often seen between the fat tissues. In Figures 14 and 15 two of lamellar corpuscles are depicted. These two lamellar corpuscles should be regarded as the embryonic types of Pacinian corpuscles, judging from their microscopic appearance.

These nerve endings in the connective tissues surrounding the coccygeal bodies seem to be important in regard to their cooperation with the physiological function of the coccygeal bodies.

Although no paraganglionic cells were observed in the stroma of coccygeal bodies, the paraganglionic tissue was observed in the connective tissues near the coccygeal body. In Figure 16 it is depicted and it should be regarded as thc coccygeal paraganglion, which is characterized by the ovoid, large, chromatin-less cells and rich nerve 


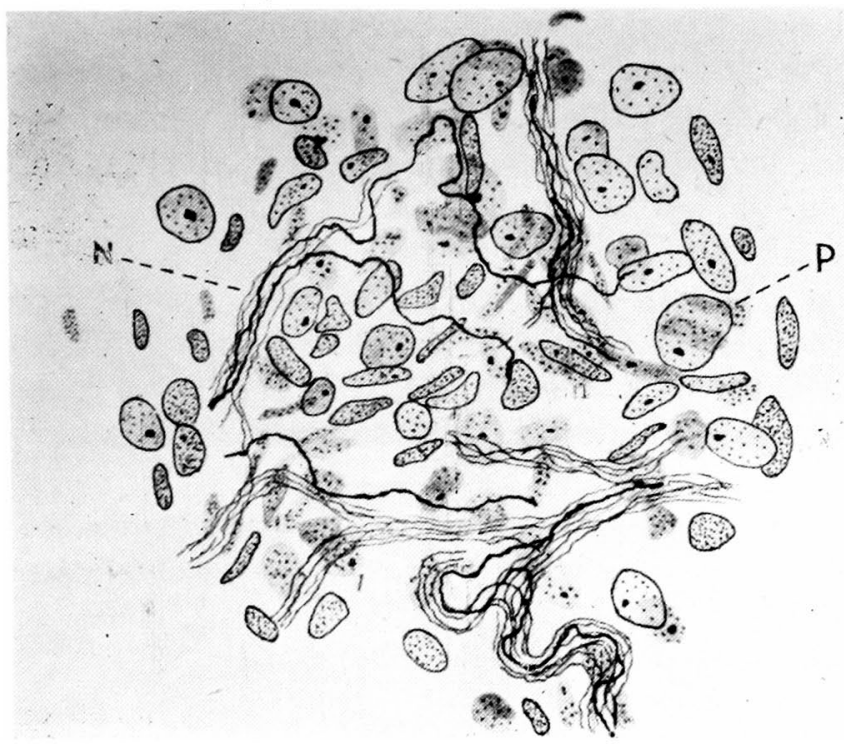

Fig. 16. A diagram of the paraganglionic tissue, which is found in the connective tissue surrounding the coccygeal bodies in human adult. Silver-impregnation method. N: Thin and thick nerve fibers, P: Paraganglionic cell.

supply.

Finally, reviewing the literature concerning the microscopic innervation of the human coccygeal bodies, there are a few papers on the subject reported by L u s $\mathrm{h} \mathrm{k}$ a (1860), $\mathrm{K} \mathrm{r}$ a u s e (1861), A r n o ld (1865), M e y e r (1866), J a k obs on (1899), S c h u ma cher (1907), Be n n i n g of f (1948), S a to (1955), C a u n and M a n a n (1958) and $\mathrm{Knoche}$ (1958). Lusch ka and A r nold described that the nerve supply in the coccygeal glands is extremely rich. $\mathrm{Kr}$ a u s and $\mathrm{M}$ e ye $\mathrm{r}$ stated that two different nerve fibers are recognizable; the single- and double-refractile fibers in the stroma of the coccygeal bodies. Jakobsson stated that abundant nerve fibers originated from the sympathetic nervous system suyply in the stroma of the coccygeal glands in a plexus-like manner and the major element of these fibers is composed of Remak's fibers. Schumacher observed the lamellar corpuscle in the neighborhood of the coccygeal bodies. Benninghoff mentioned that one often find the Vater-Pacinian corpuscles in the neighborhood of the arterio-venous anastomosis. $\mathrm{Knoche}$ (1958) has studied on the microscopic innervation of the arterio-venous anastomosis in the vascular system of the cock's comb and the human newborn's nail bed with the Bielschowsky's and Bodian's methods. 
He has stated that the encapsulated sensory endorgans composed of myelinated nerve fibers exist in the adventitia of arterio-venous anastomosis. Especially, the nervous networks consisting of nonmyelinated and myelinated nerve fibers can be observed in the arterial portion of the arterio-venous anastomosis. These nerve cndings should be regarded as the receptory endorgans of the afferent nervous systam and are morphologically compared with the nerve endings in the wall of the carotid sinus. Also $\mathrm{C}$ a $\mathrm{u}$ a and $\mathrm{Mann}$ a $\mathrm{n}$ in 1958 have stated that, human digital pacinian corpuscles are morphologically closely related with the function of the arterio-venous anastomosis.

At any rate, a clarification of the biological significance of the coccygeal bodies should be made by further physiological and morphological studies.

\section{Literature cited}

A rnold, J. (1865): Ein Beitrage zu der sog. Steissdrüse. Virch. Archiv f. path. Anat., Bd. 32.

Benning hof f, A. (1948): Arterio-venose Anastomosen. Lehrb. d. Anat. d. Mensch., Bd. 2.

C a u $n a, N$. and Mannan, G. (1958): The structure of human digital pacinian corpuscles and its functional significance. J. Anat., Vol. 92.

Jakobsson, H. (1899): Beiträge zur Kenntnis der fätalen Entwicklung der Steissdrüse. Archiv f. mikr. Anat., Bd. 53.

$\mathrm{Kn}$ och e, H. (1958): Untersuchungen über die feinere Innervation arterio-venöser Anastomosen. Ztschr. f. Anat. u. Entwickl., Bd. 120, 5 Hefte.

Kra use, W. (1861): Zur Anatomie der Steissdrüse. Ztschr. f. rat. Med., Reihe $3,10$.

Kubota, K. (1954): Contributions to the macroscopic anatomy of the glomera coccygica in man. Okajimas Fol. Anat. Japon., BJ. 18.

L u schka, H. (1860): Die Steissdrüse des Menschen. Virch. Archiv, Bd. 18.

Me ye r, G. (1866): Zur Anatomie der Steissdrüse. Ztschr. f. rat. Med., Bd. 28.

S a t o, H. (1955): On the histological structure of the coccygeal body. Hukushima Med. J., Vol. 5. (Japanese.)

$\mathrm{Sch}$ u m a che r, S. v. (1907): Über das Glomus coccygeum des Menschen und die Glomus caudales der Säugetiere. Verhand. d. anat. Gesellsch. 